\title{
Hedonic Housing Prices and the Demand for Clean Air ${ }^{1}$
}

\author{
DAVID IIARRISON, JR. \\ Department of City and Regional Planning, Harvard University, Cambridge, Massachusetts
}

AND

DANIEL L. RUBinfeld

Department of Economics and Institute of Public Policy Studies, The University of Michigan; National Bureau of Economic Research, Cambridge, Massachusetts

Received December 22, 1976

This paper investigates the methodological problems associated with the nse of housing market data to measure the willingness to pay for clean air. With the use of a hedonic housing price model and data for the Boston metropolitan area, quantitative estimates of the willingness to pay for air quality improvements are generated. Marginal air pollution damages (as revealed in the housing market) are found to increase with the level of air pollution and with household income. The results are relatively sensitive to the specification of the hedonic housing price equation, but insensitive to the specification of the air quality demand equation.

\section{INTRODUCTION}

Expressing the benefits of reduced urban air pollution concentrations in monetary terms is a difficult task, despite the fact that the general nature of the benefits is reasonably well established." Several attempts have been made to utilize economic analysis to estimate the dollar benefits of air quality improvements. One approach is to proxy willingness to pay by measuring either the added cost to society from increased air pollution, or equivalently the reduced costs associated with air quality improvement. ${ }^{3} A$ second technique infers willing-

${ }^{1}$ This research was supported by the National Bureau of Economic Research. All statistical analyses were performed on the NBER Center for Computational Research's TROLL System. We wish to thank members of the NBER for their technical advice; William Apgar, A. Myrick Freeman, Gregory Ingram, John Kain, Robert McDonald, and two anonymous referees for helpful comments on earlier drafts; Gary Fauth, Gregory Ingram, Eugene Kroch, Robert McDonald, and Ann Schnare for providing data used in this study; and Laxmi Rao of the NBER for providing helpful research assistance.

${ }^{2}$ Studies have documented the damages which high concentrations of air pollutants impose un human health, on vegetation, on various materials and fibers, and on the aesthetic elements of urban living. While urban residents perceive some of the damage, such as eye irritation, hazy skies, and dirty paint, other damage is only evident to trained researchers. For a summary of these damage studies, see Harrison [9].

${ }^{3}$ This approach has been used in a number of studies to evaluate the costs of air pollution to plants, materials, or human health. For example, Lave and Seskin [19] used statistical estimates of the effect of air pollution on morbidity and mortality rates to compute increases in health costs and decreases in earning capacity attributed to higher air pollution levels. 
ness to pay for better air quality from an analysis of the housing market, on the presumption that individuals will pay more for a unit located in an area with good air quality than for an otherwise identical unit located in an area with poor air quality. ${ }^{4}$

This paper investigates the methodological problems associatcd with the housing market approach. While several studies have used this methodology to estimate the demand for air quality improvements, they have paid little attention to the sensitivity of the results to the assumptions embedded in the procedures. $^{5}$ Using data for the Boston housing market, we generate quantitative estimates of the willingness to pay for air quality improvements and test the sensitivity of these results to alternative specifications of the basic building blocks in the procedure. Our data base is superior to others because it contains a large number of neighborhood variables (necessary to isolate the independent influence of air pollution) and more reliable air pollution data.

Section II of this paper describes the four-step procedural model which is the basis of our empirical investigations. The first step is to estimate a hedonic housing value equation with air pollution as one housing attribute; the second step is to calculate each household's willingness to pay for a marginal change in air pollution from the hedonic housing value equation; the third step is to estimate a marginal willingness-to-pay function for households in the urban area, a function that is analogous to a demand curve for clean air; and the fourth step is to use the willingness-to-pay function, along with estimates of air pollution concentrations before and after pollution controls, to calculate the per household dollar benefits of the control strategy. Section III gives empirical results for different specifications of the housing value equation, and Section IV presents the corresponding results for various specifications of the marginal willingness-to-pay function. Section V illustrates the average dollar benefits of the federal automobile emission control program to Boston area residents, emphasizing the sensitivity of the average benefit figure to alternative specifications of the housing value and willingness-to-pay functions.

\section{THE PROCEDURAL, MODEL}

In this section we present a procedural model for measuring the willingness to pay for improvements in air quality. Our model is based on a theoretical structure which assumes that households consider the level of air pollution as well as the quantity and quality of housing and other neighborhood characteristics in making their housing choices. Housing value differentials then provide the starting point for estimating households' willingness to pay for reductions in air pollutant concentrations. Since the issues associated with the theoretical construct used here have been considered in detail in other papers, we present the theory in only rudimentary form. ${ }^{6}$ Some of the important underlying assumptions are noted, but we refer the reader to the cited literature for further details.

\footnotetext{
${ }^{4}$ We stress that housing market studies of this type at best can only ascertain those benefits which are perceived by households. It is clear that individuals are not aware of all potential health hazards associated with air pollution and are often ignorant of the degree to which the air they breathe is polluted.

${ }^{5}$ Housing price studies which have investigated the willingness to pay for clear air include $[1,10,22,27$, and 35$]$.

${ }^{6}$ The most complete treatment of the theoretical issues is in [28].
} 
Our theoretical model assumes that individual households maximize a utility function

$$
U(x, h)
$$

subject to the budget constraint

$$
y=x+p(h)+T
$$

where:

$x=$ quantity of composite private goods, whose price is set equal to one'

$h=\left(h_{1}, \cdots, h_{n}\right)$ is a bundle of housing attributes, including accessibility, structure and neighborhood characteristics, and air pollution concentrations,

$y=$ annual money income,

$p(h)=$ housing (or hedonic) price function, and

$T=$ money cost of transportation.

Our specification of the utility function (2.1) implies that housing is appropriately viewed as a bundle of attributes, rather than as a single commodity. ${ }^{7}$ To simplify our discussion we shall arbitrarily associate the first housing attribute, $h_{1}$, with a single measure of air pollution and label it " $a$ ". In order to apply the calculus to the utility maximization problem for the household we assume that $U$ is strictly concave with regard to the various housing attributes (when viewed as goods rather than bads). ${ }^{8}$

The first step in our procedural model is to specify the hedonic housing value function, $p(h)$. The $p(h)$ function translates a vector of housing attributes at each location into a price which influences the decisions of both suppliers and demanders of housing attributes. ${ }^{9}$ Implicit in this description of the hedonic housing function are the following important assumptions:

(1) All consumers accurately perceive the characteristics represented by the vector $h$ at every location.

(2) There is sufficient variation in $h$ so that the function $p(h)$ is continuous, with continuous first and second partial derivatives.

(3) The market is in short-run equilibrium.

' For some applications of the hedonic approach to the analysis of housing demand, see $[4,12-15,17,22$, and 32]. For more general discussions of the hedonic approach to consumer demand, see [8, 17, 20, and 28].

${ }^{8}$ We could have generalized the specification of the utility function to allow for the household production of housing services from the housing attributes, but we chose not to do so. Such a generalization adds an additional complication which is not necessary for our purposes; but it would make explicit the fact that housing price differentials may arise from differences in household consumption technologies as well as from differences in households' tastes for housing attributes. For some insightful discussions of the relevance of household production theory for the problems of estimating hedonic price functions, see [17, 21, 22, 26, and 31].

${ }^{9}$ We have chosen to write the theoretical model in terms of annual rental prices, although our empirical work uses housing values (capitalized streams of annual rental prices) in conformity with other studies. Conceptually, rental prices are more appropriate because they reflect the market's current valuation of housing attributes. Housing values, on the other hand, reflect the market's expectations about future as well as present housing conditions. 
(4) Spatial variations in housing characteristics (including air pollution) are capitalized into differentials in housing prices. ${ }^{10}$

Note that the $p(h)$ relationship between housing attributes and house prices need not be linear. Nonlinearities may exist in part because the market may not be in long-run equilibrium-unlike the attributes of less durable commodities, housing attributes cannot be untied and repackaged to produce an arbitrary set of attributes at all locations. For example, a nonlinear relationship observed in an hedonic equation between the number of rooms and housing value may in part reflect disequilibrium supply conditions and in part reflect varying marginal benefits from extra increments of interior space. Similar conditions may hold for air pollution and other neighborhood attributes. In fact, supply conditions are more complex for neighborhood characteristics than for structural attributes since there is no long-run neighborhood attribute supply price equivalent to the construction cost for rooms and other structural components.

The second procedural step, calculating each household's willingness to pay for a marginal change in air pollution, follows from the first order condition for utility maximization (when Eq. (2.1) is maximized subject to Eq. (2.2)) with respect to the air pollution attribute, $a$. This first order condition is given below as Eq. (2.3):

$$
W_{a}(h)=\frac{\partial U / \partial(-a)}{\partial U / \partial x}=\frac{\partial p(h)}{\partial(-a)}=p_{u}(h)
$$

Equation (2.3) states that in equilibrium the household's annual willingness to pay for a small improvement in air quality $\left[W_{a}(h)\right]$ is equal to the increased cost $\left[p_{a}(h)\right]$ incurred in purchasing (or renting) a different house with identical attributes except for a marginal improvement in air quality. Thus the second step consists of calculating the derivatives of the hedonic housing price equation with respect to the air pollution attribute, i.e., $\partial p(h) / \partial(-a)$. Calculated separately for each household, this derivative is an estimate of $W_{a}(h)$, the household's willingness to pay for a marginal improvement in air pollution.

To determine each household's willingness to pay for nonmarginal improvements in air quality we need to estimate the relationship between the air pollution level and marginal willingness to pay, i.e., the $W_{a}(h)$ schedule. ${ }^{11}$ Estimating the $W_{a}(h)$ schedule is the third step in the procedural model. The $W_{a}(h)$ function is estimated in our model by regressing households' marginal valuations (the derivatives calculated in the second step for each household) on air pollu-

\footnotetext{
${ }^{10}$ A competitive market is not sufficient to guarantee that differentials in air quality will be capitalized into housing prices. For example, full capitalization may not take place in a model in which there are endogenous labor markets (see Polinsky and Rubinfeld [24] and [25] for details). An excess supply of undistinguishable low-pollution areas may also prevent full capitalization of air pollution differences.

11 The schedule we seek is the inverse of the compensated demand curve for the air quality attribute (see [5]). It can be conceptualized by considering the following experiment. Let the level of utility attained by the household in equilibrium be fixed. Then fix the household's location, its consumption of the composite good, and all housing attributes other than air quality. The total willingness to pay for a given decrease in air pollution is the maximum amount of income the household is willing to give up to keep the decreased level of air pollution. $W_{a}(h)$, the marginal willingness to pay for decreases in air pollution concentration, is equal to the derivative of the total willingness-to-pay function with respect to air pollution concentration.
} 
tion concentration and other variables (household income, for example) which may cause the demand for cleaner air to shift. Section IV presents results for several specifications of the $W_{a}(h)$ function as well as the results of estimating the $W_{a}(h)$ function from alternative hedonic housing value equations.

Before estimating the marginal willingness-to-pay function, we must ask whether it is possible to identify $W_{a}(h)$ from the available housing market data. This is a classic identification problem, since one can imagine a supply as well as a demand function for each housing attribute at every location. However, in the case of air pollution it seems reasonable to assume that the supply is either exogenously fixed or at least unresponsive to changes in household tastes, so that variations in the level of air pollution over space allow us to identify information about households' demand for clean air. ${ }^{12}$ Thus, we proceed under the assumption that it is possible to identify households' willingness to pay for clean air from the housing market data.

The fourth and final step in evaluating the dollar benefits of a scheme to improve urban air quality is to use the willingness-to-pay schedule to place a dollar value on physical improvements in air quality estimated by a meteorological airshed model. In Section V we perform such an exercise and estimate the dollar benefits of the federal automobile emission control strategy in the Boston metropolitan area. Estimates of pollutant concentrations both with and without federal automobile emission controls were obtained from a meteorological model of the Boston airshed. The per household willingness to pay for substantial reductions in air pollution can be calculated for households at each location by integrating $W_{a}(h)$ from the old concentration to the new air pollution concentration. Since the dependent variable in the first step hedonic equation is housing value, the integral of willingness to pay is an estimate of the capitalized valuc of the air quality improvement to each household. To obtain an annual value a discount rate must be applied.

The example in Section V compares results in terms of the average annual dollar benefits per household, which is calculated as a weighted average of the dollar benefits for households in each of the geographic areas (census tracts) used in the estimation procedure. Comparing average benefit figures illustrates the sensitivity of the final results to alternative specifications of the hedonic housing valuc function and of the willingness-to-pay function, the two empirical building blocks in our procedural model of benefit estimation. The specifications used in the example and explanations of their derivations are presented below in Section III (housing value equation) and Section IV (willingness-to-pay equation).

\section{HOUSING VALUE EQUATION}

This study utilizes data for census tracts in the Boston Standard Metropolitan Statistical Area (SMSA) in 1970. Following the example of most studies of this kind, we focus on the owner market. Thus, the dependent variable in our housing equation is the median value of the owner-occupied homes in the census tract.13

12 Our empirical estimates test for the importance of possible supply shifts, and we conclude that they have a minor influence on benefit estimates.

${ }^{13}$ There is some controversy about the proper dependent variable in a housing value equation. See, for example, Wieand [35] who argues that the correct dependent variable is the unit price of housing, proxied by housing value per unit of land. 
The independent variables in the equation include two structural attribute variables, eight neighborhood variables, two accessibility variables, and one air pollution variable. The pollution variable used in the empirical estimates is the concentration of nitrogen oxides $(N O X)$. The NOX variable is used to proxy air quality since the air pollution variables in our data base are so highly correlated that specifying their independent impacts on housing values in the Boston SMSA would be extremely difficult. ${ }^{14}$ Descriptions of the data we employed and full results of our estimation of the equation are given in the Appendix.

One of the major objectives in estimating the hedonic housing equation was to determine the best fitting functional form. Comparing models with either median value of owner-occupied homes $(M V)$ or $\log (M V)$ as the dependent variable, we found that the semilog version provided a slightly better fit. Using $\log (M V)$ as the dependent variable, we concentrated on estimating a nonlinear term in $N O X$; i.e., we included $N O X^{p}$ in the equation, where $p$ is an unknown parameter. Determining the proper exponent on NOX in the housing value equation is important because different exponents imply different patterns of the influence of air pollution on housing values and thus different patterns for the willingness to pay for air quality improvements.

The statistical fit in the equation was best when $p$ was set equal to 2.0, i.e., when $N O X^{2}$ was in the equation. ${ }^{15}$ This "basic equation" (see Table VII in the Appendix) is used in the remainder of the paper to generate estimates of the willingness to pay for air pollution reduction. The equation conforms well to our a priori expectations about the influence of each variable on median housing values. Virtually all coefficients have the expected sign and are statistically significant. ${ }^{16}$ The high $R^{2}(0.81)$ indicates that the variables in the equation account for much of the variation in median housing values observed in the Boston SMSA in $1970 .^{1 \pi}$ The NOX variable has a negative sign and is highly significant.

${ }^{14}$ Air pollutant variables are often not so highly correlated. There are two likely reasons why we observed a high correlation between NOX and particulates (PART), the other major air pollutant we hypothesized would influence housing values. First, while in many urban areas NOX is primarily an automobile pollutant and PART is a stationary source pollutant, in Boston only 79,388 tons out of an estimated 201,743 tons of NOX emissions were accounted for by automobile emissions. Since the stationary source emitters of both NOX and PART tend to be in central city zones, the result is a high correlation between the two variables, which is not observed in urban areas in which automotive emissions account for the bulk of total NOX emissions. Second, the true correlation between NOX and PART is somewhat overstated because the TASSIM model generates data for 122 zones, not 506 census tracts. Translating zonal data into census tract data tends to overstate the correlation because relatively more census tracts are located in center city zones in which PART and NOX levels tend to be most highly correlated.

${ }_{15}$ The exponent was estimated by performing a grid search over alternative parameter values for $p$ in the term $N^{\prime-1} /(p-1)$. The usefulness of this particular transformation of the NOX variable is described in Box and Cox [3] and in Kmenta [16, pp. 467-468]. The value for $p$ was estimated by a grid search rather than by direct nonlinear estimation because of computational difficulties we encountered with the nonlinear estimation method.

${ }^{16}$ There are some exceptions. For example, the $A G E$ variable is positive and statistically insignificant, probably because in Boston AGE does not correlate closely with housing quality (since many older units are of high quality).

${ }_{17} \mathrm{We}$ were concerned that multicollinearity among neighborhood, accessibility, and air quality variables might be a problem. (The simple correlations among variables appear in Table VI.) In fact, we did find that when both NOX and particulate concentration (PART) appear in the same equation, collinearity does become serious. In some specifications with 
Assessing the quantitative importance of the NOX coefficient $(-0.0064)$ requires some calculation because, with the nonlinear specification, the change in housing value resulting from a one pphm (part per hundred million) change in NOX concentration depends upon the level of NOX and the levels of the other explanatory variables. When $N O X$ and the other variables take on their mean values, the change in median housing values from a one pphm change in NOX is $\$ 1613 .{ }^{18}$

We also estimated the same housing value equation substituting PART for NOX (see Table VII). The coefficient of $P A R T^{4}$ is negative and statistically very significant. ${ }^{19}$ In addition, the coefficients of the nonpollution variables are virtually the same with PART or NOX in the equation, adding credence to the view that the various pollution variables are reflecting households' aversion to pollution generally rather than to individual pollutants.

While $N O X^{2}$ was determined to be the superior $N O X$ term, the nonlinear least squares grid search suggested that we could not place great confidence in the precise exponent of $2 .{ }^{20}$ Because of the distinct possibility that the true value for $p$ is some value other than 2, our later uses of the housing value equation include results for exponents of the NOX variable ranging from 1.0 (the linear semilog form) to 3.0. As an additional test of the sensitivity of the results to nonlinearities in $N O X$, we estimated an equation including both $\log (N O X)$ and $\log (N O X)^{2}$, the first two terms in a Taylor series approximation to $N O X^{p}$, and one including both $N O X$ and $N O X^{2}$. Most of the coefficient estimates were not substantially different from those in the "basic equation" with $N O X^{2}$ as the sole air pollution term. The application in Section $\mathrm{V}$ provides comparisons of benefit estimates when these other formulations are used.

The "basic equation" was substantially unchanged when corrected for heteroscedasticity. Because our empirical analysis is based on census tract data rather than individual observations we anticipated that heteroscedasticity might be a

both NOX and PART appearing, the coefficient on NOX became positive. However, the problem is simplified if one is willing to alter the specification to include a single pollutant measure. To test for the presence of multicollinearity with a single pollutant measure, we experimented to see whether the use of ridge regression techniques might alter our parameter estimates (they did not). In addition, we did a singular value decomposition of the matrix of explanatory variable data as described in Belsley and Klema [2]. The singular value decomposition is a numerical analysis technique which is useful for determining the extent to which there are linear dependencies among the columns of the explanatory variable matrix. Specifically, the $N x k$ matrix $X$ is decomposed as $X=U \Sigma V^{\prime}$, where $\Sigma$ is a diagonal matrix whose diagonal elements (called singular values) are the square roots of the eigenvalues of $X^{\prime} X$. Low singular values imply near linear dependencies and thus a severc multicollincarity problem. The relatively high values we obtained indicated that multicollinearity does not permit a serious problem in estimating the housing value equation.

${ }^{18}$ We were also concerned about the sensitivity of the model parameters to the data. Tests of this kind, which involve reestimating the model without one or more data points, are described in detail in Welsch [34]. In general, the coefficient on NOX is quite insensitive to the omission of individual or small groups of data points.

${ }^{19}$ The nonlinear estimation procedure using PART results in an exponent of 4.0 , and thus the equation listed in Table VII for PART uses PART ${ }^{4}$ as the variable.

${ }^{20}$ Because we used a grid search estimation procedure, we were not able to determine an exact standard error for $p$. However, by using a standard nonlinear estimation routine and an initial estimate of $p=2$, we were able to approximate the asymptotic standard error of $p$ as being equal to 1.3 . 
problem. To test for heteroscedasticity we applied a Park-Glejser procedure to the "basic equation." On this basis we rejected the null hypothesis of homoscedasticity at the $5 \%$ level. ${ }^{21}$ To correct for heteroscedasticity we reestimated the housing value equation using weighted least squares; the result is presented in Table VII. Most of the coefficients wore essentially unchanged, with the cocfficient on $N O X^{2}$ falling in absolute value from -0.0064 to -0.0058 . The example in Section $\mathrm{V}$ includes results which account for this heteroscedasticity correction in the housing value equation.

Changes in the specification of the nonpollution variables in the housing value equation did change the results substantially. When the two accessibility variables, weighted distance to Boston area employment centers (DIS) and the index of accessibility to radial highways ( $R A D)$ were deleted; the coefficient of $N O X^{2}$ changed from -0.0064 to -0.0036 . Because concentrations of $N O X$ in Boston are higher in areas closest to the major employment centers and radial highways, deleting $D I S$ and $R A D$ from the equation tends to reduce the measured impact of NOX concentrations on housing values. The coefficient of NOX with $D I S$ and $R A D$ omitted reflects both the disadvantages of greater NOX concentrations and the advantages of greater accessibility. It is, therefore, substantially biased. The same specification bias occurs when proportion of the population that is lower status (LSTAT) is deleted from the equation, except that the direction of bias is the opposite. The coefficient of NOX changes from -0.0064 to -0.0081 when LSTAT is eliminated. Deleting LSTAT tends to credit NOX concentration with some of the neighborhood disamenities resulting from a high proportion of lower status households. These alternative specifications illustrate the dangers of interpreting coefficients in poorly specified equations. We discuss the quantitative impact of the specification differences on the calculated willingness to pay for improved air quality in Section $V$.

\section{WILLINGNESS-TO-PAY EQUATION}

By calculating the derivative of the housing value equation with respect to NOX (the second step in our procedural model), we obtain information on the amount of money that households would be willing to pay for small reductions in air pollution levels in their census tracts. As discussed in Section II, this information is used in the third step to estimate a schedule relating willingness to pay for marginal improvements to the level of air pollution and other variables. Table I presents five formulations of the willingness-to-pay equation, all based on the "basic" housing value equation. The first two equations assume a linear relationship between the willingness to pay for a marginal change in NOX concentration and the NOX level, household income (INC), and (in Eq. (4.2)) persons per dwelling unit $(P D U)$. The other three equations postulate a log-log relationship.".2

21 We regressed the logarithm of the square of the residuals against the logarithm of total dwelling units in a linear regression. The intercept of -1.54 was insignificant, but the slope of -0.48 was significant at the $5 \%$ level (the $t$ value was -2.44 ). This test is described in $[6,7$, and 23].

22 Our willingness-to-pay equations are estimated using ordinary least squares under the assumption that the supply of air pollution is perfectly inelastic at each location. 'This assumption is reasonab!e in terms of short-run crosssection analysis, but may be suspect in a longer run context. To test the sensitivity of our results to the potential simultaneity problem caused 
TABLE I

Willingness to Pay for Air Pollution Reduction Based on Nonlinear Housing Value Equation ${ }^{n}$

\begin{tabular}{|c|c|c|}
\hline \multicolumn{2}{|r|}{ Linear Equations* } & $R^{2}$ \\
\hline$(4.1)$ & $W=-1040+209 \mathrm{NOX}+12.1 \mathrm{INC}$ & 0.52 \\
\hline$(4.2)$ & $W=-581+189 \mathrm{NOX}+12.4 I N C-119.8 P D U$ & 0.55 \\
\hline \multicolumn{3}{|c|}{ Log-log Equations* } \\
\hline (4.3) & $\log W=1.08+0.87 \log N O X+1.00 \log I N C$ & 0.62 \\
\hline (4.4) & $\log W=1.05+0.78 \log N O X+1.01 \log I N C-0.24 \log P D U$ & 0.64 \\
\hline \multirow[t]{2}{*}{$(4.5)$} & $\log W=2.20+0.97 \log N O X+0.80 \log I N C-0.03\left(Y_{1}\right)(\log N O X)$ & \\
\hline & $-0.07(Y 2)(\log N O X)$ & 0.64 \\
\hline
\end{tabular}

* All coefficients are significant at the 0.01 level.

${ }^{a} W=$ marginal willingness to pay $(\$) ; N O X=$ nitrogen oxides concentration in pphm; $I N C=$ household income in hundreds of dollars; $P D U=$ persons per dwelling unit; $Y 1=1$ when $95 \geq I N C>130,0$ otherwise; $Y 2=1$ when $I N C \geq 130$, 0 otherwise.

The relationship between marginal willingness to pay, NOX level and household income implied by these results is depicted graphically in Fig. 1 for Eq. (4.3). The three curves illustrate the marginal willingness to pay as a function of NOX level for three income levels, low ( $\$ 8500$ per year), medium ( $\$ 11,500$ per year), and high ( $\$ 15,000$ per year). The positive slope for all curves implies that households perceive at least some damages from air pollution to be greater at higher pollution levels. Thus the willingness to pay for marginal reductions is greater as pollution levels increase. Moreover, these differences seem to be substantial for the NOX levels existing in Boston census tracts in 1970, where the average NOX level ranges from approximately $3 \mathrm{pphm}$ to $9 \mathrm{pphm}$. For example, a middle-income household earning $\$ 11,500$ per year would be willing to pay roughly $\$ 800$ for a $1 \mathrm{pphm}$ improvement in NOX when the NOX level is 3 pphm, while the willingness-to-pay figure would jump to approximately $\$ 2200$ when the NOX level is $9 \mathrm{pphm}$. Figure 1 also shows that the willingness to pay for a marginal improvement in NOX concentration is greater for households in higher income groups.

The straight line at $\$ 2052$ illustrates the willingness-to-pay curve implicit in a simple linear housing value equation (i.e., with $M V$ as the dependent variable and NOX in the equation) in which households are assumed to place the same dollar value on a $1 \mathrm{pphm}$ improvement in NOX regardless of the existing level of air pollution and their income level. Our results suggest that the assumption of a constant willingness to pay is unwarranted. Indeed, it appears that the total

by a less than perfectly inelastic supply of air pollution, we estimated the willingness-to-pay equation using two-stage least squares, with INDUS, $P D U$ (possible supply variables) and INC appearing in the first stage reduced form equation. The two-stage least squares estimate of the pollution elasticity fell to 0.70 , while the income elasticity fell to 0.93 . These changes in elasticity had little impact on the nonmarginal benefit calculations described in the next section. We also tested the log-log willingness-to-pay equation for heteroscedasticity by applying the Park-Glejser test described in the previous section. After rejecting the null hypothesis at the $5 \%$ level, we reestimated the willingness-to-pay equation using weighted least squares. The weighted least squares equation was $\log (W)=0.91+0.96 \log ($ NOX $)+$ $1.01 \log (I N C)$, with all parameters significant at the $1 \%$ level. We report the impact of this adjustment on estimated benefits in the following section. 
willingness to pay for air pollution reduction varies a great deal depending upon the existing air pollution levels in the urban area and the income profile of the population.

Figure 1 also indicates that the premium that high income households are preparcd to pay rises as the NOX level increases. At low NOX levcls ( $3 \mathrm{pphm}$ ), the differential for households earning $\$ 11,500$ compared to households earning $\$ 8500$ is only $\$ 200$. But at high NOX levels ( $9 \mathrm{pphm}$ ), the differential is about $\$ 700$. Equation (4.5) includes a test of the hypothesis that households in different income groups have different elasticities of willingness to pay with respect to NOX levels. Dummy variable interaction terms are presented for middle income households ( $\$ 9500$ to $\$ 13,000$ ) and high income households (over $\$ 13,000$ ). The negative coefficients on both interaction terms imply that the elasticity of willingness to pay with respect to NOX level is 0.97 for the low income group, 0.94 for households in the median income group, and 0.90 for households in the high income group. ${ }^{23}$ The larger willingness-to-pay elasticity for lower income households suggests that as air pollution is reduced (other things equal), the marginal valuation of air quality improvements declines more rapidly for lower income households than for middle-income and high-income households. ${ }^{24}$

\section{AN ILLUSTRATION: THE WILLINGNESS TO PAY FOR FEDERAL AUTOMOBILE EMISSION CONTROLS}

To illustrate the fourth and final step of our procedural model, this section estimates the housing value benefits associated with a program to improve Boston area air quality. Specifically, we consider the benefits from the federal automobile emission control strategy, in which the federal government established tailpipe emission standards for new cars beginning in model year 1971. These emission standards became increasingly stringent up to the 1978 year model, when a roughly $90 \%$ reduction from the 1970 levels is mandated for nitrogen oxides, hydrocarbons, and carbon monoxide.

The purpose of this illustration is not to determine the precise dollar figure for benefits from this control strategy. Rather, it is to illustrate the sensitivity of the benefit figure to different specifications of the housing value and willingness-topay equations. Much greater care would be necessary to separate out the independent influence of the automobile pollutants from the overall air pollution in the Boston area in order to estimate with confidence the precise dollar value of the fedcral automobile emission control program..$^{25}$

${ }^{23}$ These elasticities are statistically different from each other at the 5\% level.

${ }^{24}$ We do not present any results in which housing attributes other than air quality appear in the willingness-to-pay equation. We found that the inclusion of other housing attributes had very little effect on our estimates of the willingness to pay for nonmarginal changes in air quality. However, it is possible that some housing attributes are complementary to (or substitutable with) reduced air pollution so that households consuming greater (lesser) quantities of those attributes would be willing to pay more (less) for NOX improvements. For example, we tested the hypothesis that air quality and the number of rooms ( $R M)$ are complimentary, and the results confirmed the hypothesis (all $t$ tests were highly significant):

$$
\log W=0.71+0.81 \log (N O X)+0.78 \log (I N C)+0.84 \log (R M) .
$$

${ }^{25}$ It is difficult to say with assurance whether our benefit figures are overestimates or underestimates of the true dollar value that Boston households place on the air quality improvements generated by stringent auto controls. Benefits may be overestimated because the 


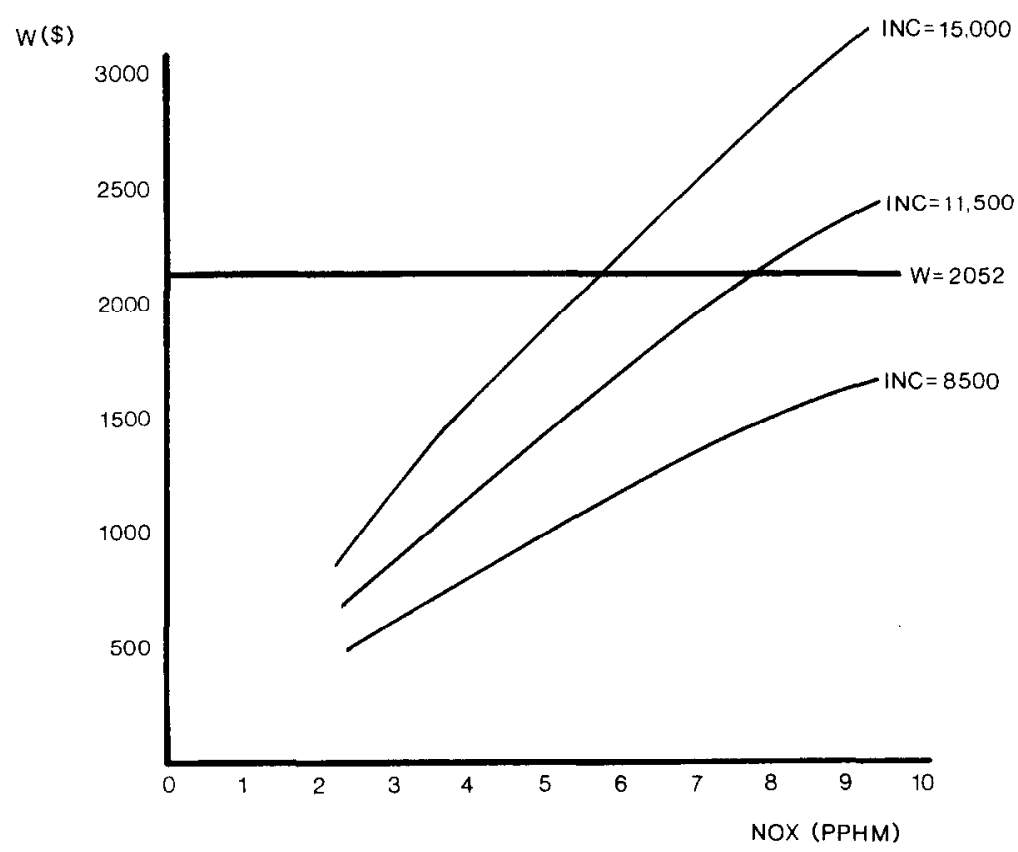

Fic. 1. Willingness to pay for $1 \mathrm{pphm}$ improvement in NOX concentration, by NOX level for households in three income levels (log-log version).

The physical changes in NOX concentrations in each of the 506 Boston SMSA census tracts were calculated for 1990 using the Transportation and Air Shed Simulation Model (TASSIM). ${ }^{26}$ The average dollar value of these physical improvements in NOX concentration depends upon the amount each household is willing to pay for the physical improvement they experience. ${ }^{27}$ The results given in Sections III and IV for the first three steps permit us to estimate the average dollar value under various assumptions about the function relating housing values to $N O X$ concentration and other variables, and the function relating willingness to pay for marginal changes in $N O X$ to the $N O X$ level and various household characteristics. The full range of potential estimates of average dollar benefits calculated in the fourth step can be visualized as a matrix with

NOX variable may reflect the disbenefits associated with particulates and other nonauto pollutants. Note that our calcu'ations do not assume any reduction in nonauto sources of NOX (the physical changes in NOX predicted from auto controls are relatively small because of the large contribution of other NOX sources in the Boston airshed), and thus the auto benefits are not overstated for that reason. Auto benefits may be understated because the value of reducing carbon monoxide and hydrocarbon emissions may not be taken into account and because the full dollar benefits of the auto emission control strategy includes some benefits which are not likely to be reflected in housing prices.

${ }^{26}$ For a description of the TASSIM model, see Ingram and Fauth [11]. The estimates of 1990 NOX concentrations in Boston subareas were obtained in TASSIM by substituting the emissions characteristics of the 1990 controlled fleet for the 1970 fleet emissions figures used in the basic run. The physical benefits of the federal automobile emission program are then simply the difference between NOX concentrations in 1970 and 1990.

27 Our calculations assume that households are only willing to pay for air quality improvements in their residence tract. Some household members may also experience benefits in other tracts, where they work, shop, or visit. 
the rows corresponding to different formulations of the housing value equation and the columns corresponding to different formulations of the willingness-topay equation. However, it is not necessary to present the full matrix of estimates to gain an appreciation of the sensitivity of the results to alternative specifications of the two building block cquations.

Table II presents average annual benefits per household for four formulations of the housing value equation and two versions of the willingness-to-pay equation. The largest estimate of average household benefits ( $\$ 118)$ is derived from a linear housing value equation. ${ }^{28}$ This is the specification often employed in previous housing value studies. The linear equation contains the implicit assumption that every unit reduction in NOX concentration is valued identically by all households. The willingnes-to-pay function for all households is then a horizontal line at the unit "price" for NOX estimated by the linear housing value equation (see Fig. 1, where $W=\$ 2050$ ).

The other results reported in Table II are equations based on a semilog specification of the housing value equation (which inherently allows for variations in marginal willingness to pay) that differ in the exponent assigned to NOX. The benefit estimate in which we place the greatest confidence is obtained from the semilog housing value equation with the exponent of NOX equal to 2 (the "basic equation") and the log-log willingness-to-pay equation. This combination yields a benefit estimate of $\$ 83$ per household per year, approximately $30 \%$ below the figure based on a linear housing value equation. ${ }^{29}$ This $\$ 83$ estimate takes into account the fact that households' willingness to pay for marginal reductions in air pollution may vary with the pollution concentration (a movement along the willingness-to-pay curve; see Fig. 1), as well as with household income (a shift in the willingness-to-pay curve). The benefit estimate of $\$ 92$ given in the second column indicates that if one were to allow willingness to pay to vary by tract but not be systematically related to the level of pollution and income (i.e., neglect the willingness-to-pay function), benefits would be overestimated by approximately $11 \%$.

Calculating average benefit figures for the entire SMSA ignores variations in average benefits enjoyed by subgroups of the population classified by income, race, and other variables. To illustrate the distributional information that our

28 The formula used to calculate annual benefits per household in 1990 for the linear specification is:

$$
A B=\frac{\sum_{i=1}^{N}\left(H H_{i}\right)\left(\Delta N O X_{i}\right)\left(a_{p}\right)}{10 \sum_{i=1}^{N}\left(H H_{i}\right)}
$$

where: $A B=$ average annual benefits per household (in dollars) from emission controls; $H H_{i}=$ number of households in census tract $i ; \Delta N O X_{i}=$ improvement in NOX concentrations in tract $i$ in 1990 compared to 1970; $a_{p}=$ coefficient of NOX from linear housing value equation; $N=$ number of census tracts in sample $(N=506)$. Dividing average benefits by 10 , implying a discount rate of $10 \%$, yields an estimate of average annual benefits.

${ }^{29}$ The average dollar value is calculated as in the previous footnote, except that average benefit per household, $B_{i}$, is substituted for the product $\left(\Delta N O X_{i}\right)\left(a_{n}\right) . B_{i}$ is calculated as follows:

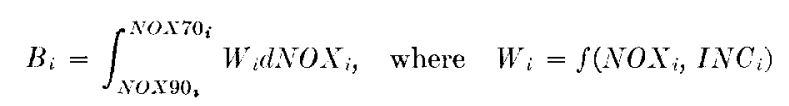


TABLF, II

Average Annual Benefits per Household in Boston SMSA From Change in NOX Levels due to Automobile Emission Controls: Based on Different Housing Value Equations

\begin{tabular}{|c|c|c|}
\hline \multirow{2}{*}{$\begin{array}{c}\text { Housing vahe } \\
\text { equation }\end{array}$} & \multicolumn{2}{|c|}{ Willingness-to-Pay equation } \\
\hline & $\begin{array}{c}\text { Assume } \\
W=f(N O X, I N C) \\
(\log -\log \text { version })\end{array}$ & $\begin{array}{c}\text { Assume W } \\
\text { constant }\end{array}$ \\
\hline Linear & - & $\$ 118.00$ \\
\hline Semi $\log (P=1)$ & $\$ 101.26$ & 105.26 \\
\hline Semi $\log (P=2)$ & 83.00 & 92.03 \\
\hline Semi log $(P=3)$ & 59.17 & 78.32 \\
\hline
\end{tabular}

model can generate, we estimated the average benefits for three income classes. ${ }^{30}$ We found that low income households received the highest benefit ( $\$ 93)$, while high income households had the lowest average benefit ( $\$ 71)$. Low income households receive the greatest dollar benefit because they live in highly polluted areas that experience the greatest reduction in pollution from auto emission controls.

The remaining results in Table II are tests of the sensitivity of benefits to the exponent of NOX in the housing value equation. Altering the exponent on the air pollution term from 2.0 yields markedly different average benefit figures. Average benefits are greatest for the semilog case (among the three values listed in Table II) when the exponent is put at 1.0, i.e., when NOX is entered in the equation. For the case when the $\log -\log$ willingness-to-pay equation is used to generate average benefits, average benefits increase from $\$ 83$ to $\$ 101$ when the exponent changes from 2.0 to 1.0 . This change represents a $22 \%$ increase in average benefits. The change is just as dramatic when the exponent is assumed to be 3.0 rather than 2.0. Average benefits decline from their baseline value of $\$ 83$ to only $\$ 59$, a $29 \%$ drop. Since we estimated a standard error of 1.3 on the exponent of 2.0 for $N O X$, we conclude that the "true" value for average benefits in this case could easily range from approximately $\$ 60$ per year to over $\$ 100$ per year, depending upon which specification of the NOX variable is the "true" one.

We also tested for the sensitivity of average benefits per household to different specifications of the willingness-to-pay function when the "basic" housing value equation was used. These results (not reported here) indicate that the choice of a specific willingness-to-pay function does not greatly influence the average benefit figure. For example, when the linear rather than the $\log -\log$ version of the willingness-to-pay equation with NOX and $I N C$ is used, average benefits only increase from $\$ 83$ to $\$ 84$.

A great many other specifications of the housing value equation are possible. To explore the sensitivity of the average benefit figures to different housing value equations, we calculated average benefit figures using a single willingness-to-pay equation (the $\log -\log$ version with $N O X$ and $I N C$ ) and several versions of the

\footnotetext{
:3 Income groups were based on the following classification of census tracts by average household income: low income: $=<\$ 9500$ per year; middle income: $=\$ 9500-\$ 13,000$ per year; high income: $=>\$ 13,000$ per year.
} 
I. Housing price specifications

(1) Basic (semilog, with $N O X^{2}$ )

(2) Delete $D I S$ and $R A D$

(3) Delete $L S T A T$

(4) Add $N O X$

(5) Substitute $\log (N O X)$ and $(\log N O X)^{2}$

(6) Income submarkets

(7) Distance submarkets

(8) Low status submarkets

II. Statistical Corrections

(9) Heteroscedasticity in housing value equation

(10) Heteroscedasticity in willingness-to-pay equation

(11) Simultaneity in willingness-to-pay equation
83.00

47.08

104.64

78.52

$65.13^{b}$

59.84

49.35

75.65

76.03

84.07

82.31

${ }^{a}$ Unless otherwise indicated, all figures are based on the log-log specification of the willingnessto-pay equation: $\log W=f[\log (N O X), \log (I N C)]$.

${ }^{b}$ This figure is based on the linear specification of the willingness-to-pay equation.

housing value equation. These results are listed in Table III. The baseline figure is $\$ 83$, which is the average benefit obtained using the "basic" housing value equation.

The first experiment consisted of deleting some variables from the "basic equation." Average benefits proved to be very sensitive to these experiments. When the two accessibility variables DIS and RAD were omitted from the specification, average benefits fell from $\$ 83$ to $\$ 47$. This decrease occurs because when DIS and RAD are omitted from the equation, some of the advantages of greater accessibility cancel out the disadvantages of higher NOX concentrations. Therefore, the benefits of reduced pollutant concentrations appear smaller. The same confusion occurs when LSTAT is deleted from the equation, except that omitting LSTAT increases the calculated average benefits from $\$ 83$ to $\$ 105$. When LSTAT is not in the equation, the empirical results attribute to high NOX levels some of the perceived disbenefits of being in an area with large proportions of lower status households. These results show that the benefits of reduced air pollution concentration may be substantially overestimated or underestimated if the equation used to describe the structure of the housing market is misspecified. One should be particularly suspicious of estimates of dollar benefits from air pollution reductions which are based on formulations omitting important neighborhood and accessibility variables which are likely to be quite highly correlated with air pollution.

The second experiment reported in Table III is to modify the housing value equation by including other nonlinear functional relationships for NOX. Including both $N O X$ and $\mathrm{NOX}^{2}$ in the housing value equation somewhat decreases the average benefits, although the decline is not very great (from $\$ 83$ to $\$ 79$ ). A more substantial decrease occurs when $\log N O X$ and $(\log N O X)^{2}$ are substituted 
for $N O X^{2}$ in the equation. Average benefits in that case decline to $\$ 65 .^{31}$ These results provide additional evidence of the sensitivity of the average benefit measure to the form in which air pollution influences housing values.

The next three estimates in Table III $[(6),(7)$, and (8)] provide the results of experiments which assume that the Boston SMSA housing market is actually a series of distinct submarkets. The aggregative census tract data used in this study do not allow us to calculate average benefits for detailed specifications of housing submarkets. ${ }^{32}$ However, we tested for the variations in the average benefits when submarkets were postulated based on household income (three categories: low income, medium income, and high income), on accessibility to employment (two categories: accessible, not accessible), and on socioeconomic status (two categories: high status, low status). The average benefits were calculated for the submarket cases by estimating separate housing market equations (the "basic equation"), using the results to estimate a single willingness-to-pay function to calculate household benefits for each tract in the various submarkets, and then calculating average benefits from the Boston SMSA as a whole. While the specifications of the submarkets in these experiments are crude, the results in Table III indicate that the presence of submarkets may decrease average benefits substantially. In the most extreme case, when two submarkets are defined in terms of accessibility to major employment centers, the average benefits fall from $\$ 83$ to $\$ 49$. The $\$ 49$ figure represents approximately a $60 \%$ decline from the $\$ 118$ estimate based on the linear housing value equation.

The final estimates of average benefits in Table III reflect corrections for heteroscedasticity in the housing value equation and heteroscedasticity and simultaneity in the willingness-to-pay equation. The average benefit figures in Table III indicatc that correcting for these possible statistical problems has a relatively small effect on the estimate of average benefits, although the average benefit figure does decline to $\$ 76$ when a correction is made in the housing value equation.

\section{CONCLUSION}

Most empirical studies which attempt to measure the willingness to pay for cleaner air from housing value differentials (such as Ridker and Henning [27]) estimate a hedonic equation in which housing values are regressed against pollution levels as well as other housing attributes. Freeman [5] and Small [30] have argued that the benefit estimation procedure used by Ridker and Henning and others is correct for valuing marginal improvements in air quality. But in using these regression results to estimate the total benefits arising from a nonmarginal improvement in air quality, Ridker and Henning and other researchers implicitly assume that the value placed on a marginal improvement in air pollution concentration is independent of the level of air pollution and independent

31 This $\$ 65$ figure is based on a linear rather than a log-log version of the willingness-topay equation (because a $\log -\log$ formulation could not be estimated), so the $\$ 65$ figure is not directly comparable to the $\$ 83$ figure. However, our results clearly indicate that the functional form of the willingness-to-pay equation has a small influence on average benefits.

:2 Our attempts to define submarkets based on cross-classifications of several variables (the percent Black population in the census tract, the average tract income, the accessibility of the tract to employment centers, and the school quality in the tract) failed because many of the variables were constant or nearly constant within the submarkets. This result is a function of using average values for census tracts rather than individual observations on households. 
TABLE IV

Variables used in the Housing Value Lquations

\begin{tabular}{|c|c|c|}
\hline Variable & Definition & Source \\
\hline \multicolumn{3}{|l|}{ Dependent } \\
\hline$M V$ & Median value of owner-occupied homes. & 1970 U.S. Census \\
\hline \multicolumn{3}{|l|}{ Structural } \\
\hline$R M$ & $\begin{array}{l}\text { Average number of rooms in owner units. } R M \text { repre- } \\
\text { sents spaciousness and, in a certain sense, quantity of } \\
\text { housing. It should be positively related to housing } \\
\text { value. The } R M^{2} \text { form was found to provide a better } \\
\text { fit than either the linear or logarithnie forms. }\end{array}$ & 1970 U. S. Census \\
\hline$A G E$ & $\begin{array}{l}\text { Proportion of owner units built prior to } 1940 \text {. Unit } \\
\text { age is generally related to structure quality. }\end{array}$ & 1970 U. S. Census \\
\hline \multicolumn{3}{|c|}{ Neighborhood } \\
\hline$B$ & $\begin{array}{l}\text { Black proportion of population. At low to moderate } \\
\text { levels of } B \text {, an increase in } B \text { should have a negative } \\
\text { infiuence on housing value if Blacks are regarded as } \\
\text { undesirable neighbors by Whites. However, market } \\
\text { discrimination means that housing values are higher } \\
\text { at very high levels of } B \text {. One expects, therefore, a } \\
\text { parabolic relationship between proportion Black in a } \\
\text { neighborhood and housing values. }\end{array}$ & 1970 U. S. Census \\
\hline ISSTAT & $\begin{array}{l}\text { Proportion of population that is lower status }=\frac{1}{2} \\
\text { (proportion of adults without some high school educa- } \\
\text { tion and proportion of male workers classified as } \\
\text { laborers). The lngarithmic specification implies that } \\
\text { socioeconomic stalus distinctions mean more in the } \\
\text { upper brackets of society than in the lower classes. }\end{array}$ & 1970 U. S. Census \\
\hline CRIM & $\begin{array}{l}\text { Crime rate by town. Since CRIM gauges the threat to } \\
\text { well-being that households perceive in various neigh- } \\
\text { borhoods of the Boston metropolitan area (assuming } \\
\text { that crime rates are generally proportional to people's } \\
\text { perceptions of danger) it should have a negative effect } \\
\text { on housing values. }\end{array}$ & FBI $(1970)$ \\
\hline$Z Z N$ & $\begin{array}{l}\text { Proportion of a town's residential land zoned for lots } \\
\text { greater than } 25,000 \text { square feet. Since such zoning re- } \\
\text { stricts construction of small lot houses, we expect } Z N \\
\text { to be positively related to housing values. A positive } \\
\text { coetticient may also arise because zoning proxies the } \\
\text { exclusivity, social class, and outdoor amenities of a } \\
\text { community. }\end{array}$ & $\begin{array}{l}\text { Metropolitan Area } \\
\text { Planning Commission } \\
\text { (1972) }\end{array}$ \\
\hline INDUS & $\begin{array}{l}\text { Proportion nonretail business acres per town. INDUS } \\
\text { serves as a proxy for the externalities associated with } \\
\text { industry - noise, heavy traffic, and unpleasant visual } \\
\text { effects, and thus should affect housing values negatively. }\end{array}$ & $\begin{array}{l}\text { Vogt, Ivers, and } \\
\text { Associates [33] }\end{array}$ \\
\hline$T A X$ & $\begin{array}{l}\text { Full value property tax rate }(\$ / \$ 10,000) \text {. Measures } \\
\text { the cost of public services in each community. Nomi- } \\
\text { nal tax rates were corrected by local assessment ratios } \\
\text { to yield the full value tax rate for each town. Intra- } \\
\text { town differences in the assessment ratio were difficult } \\
\text { to obtain and thus not used. The coefficient of this } \\
\text { variable should be negative. }\end{array}$ & $\begin{array}{l}\text { Massachusetts Tax- } \\
\text { payers Foundation } \\
(1970)\end{array}$ \\
\hline
\end{tabular}


TABLF, IV-Continued

\begin{tabular}{|c|c|c|}
\hline Variable & Definition & Source \\
\hline P'TRATIO & $\begin{array}{l}\text { Pupil-teacher ratio by town school district. Measures } \\
\text { public sector benefits in each town. The relation of the } \\
\text { pupil-teacher ratio to school quality is not entirely } \\
\text { clear, although a low ratio should imply each student } \\
\text { receives more individual attention. We expect the sign } \\
\text { on PTRATIO to be negative. }\end{array}$ & $\begin{array}{l}\text { Massachuset ts Dept. of } \\
\text { Education }(1971-1972)\end{array}$ \\
\hline$C H A S$ & $\begin{array}{l}\text { Charles River dummy: }=1 \text { if tract bounds the Charles } \\
\text { River; }=0 \text { if otherwise. CHAS captures the amenities } \\
\text { of a riverside location and thus the coefficient should } \\
\text { be positive. }\end{array}$ & $\begin{array}{l}1970 \text { U. S. Census } \\
\text { Tract maps }\end{array}$ \\
\hline \multicolumn{3}{|l|}{ Accessibility } \\
\hline DIS & $\begin{array}{l}\text { Weighted distances to five employment centers in the } \\
\text { Boston region. According to traditional theories of } \\
\text { urban land rent gradients, housing values should be } \\
\text { higher near employment centers. DIS is entered in } \\
\text { logarithm form; the expected sign is negative. }\end{array}$ & Schnare $[29]$ \\
\hline$R A D$ & $\begin{array}{l}\text { Index of accessibility to radial highways. The highway } \\
\text { access index was calculated on a town basis. Good } \\
\text { road access variables are needed so that auto pollution } \\
\text { variables do not capture the locational advantages of } \\
\text { roadways. RAD captures other sorts of locational ad- } \\
\text { vantages besides nearness to workplace. It is entered } \\
\text { in logarithmic form; the expected sign is positive. }\end{array}$ & MIT Boston Project \\
\hline \multicolumn{3}{|l|}{ Air Pollution } \\
\hline NOX & $\begin{array}{l}\text { Nitrogen oxide concentrations in pphm (annual aver- } \\
\text { age concentration in parts per hundred million). }\end{array}$ & TASSIM \\
\hline$P A R T$ & $\begin{array}{l}\text { Particulate concentrations in } \mathrm{mg} / \mathrm{h} \mathrm{cm}^{3} \text { (annual aver- } \\
\text { age concentration in milligrams per hundred cubic } \\
\text { meters). }\end{array}$ & TASSIM \\
\hline
\end{tabular}

TABLE V

Summary Statistics for Housing Value Equation Variables

\begin{tabular}{lcc} 
Variable & Mean & SD \\
MV & 22,532 & 9,197 \\
RM & 6.28 & 0.70 \\
AGE & 68.6 & 28.1 \\
IB & 0.06 & 0.18 \\
ISTAT & 0.13 & 0.07 \\
CRIM & 3.61 & 8.60 \\
ZN & 11.36 & 23.32 \\
INDUS & 11.13 & 6.86 \\
TAX & 408.2 & 168.5 \\
PTRATIO & 18.5 & 2.16 \\
DIS & 3.79 & 2.10 \\
RAD & 9.55 & 8.70 \\
TOX & 5.55 & 1.16 \\
PART & 6.31 & 1.50 \\
\hline
\end{tabular}


of household income and tastes. This is equivalent to assuming a linear damage function for air pollution that is identical for all households.

The four-step estimation procedure used in this study allows us to conclude that marginal air pollution damages, at least as revealed in the housing market, incrcasc with the level of air pollution and increase with the level of houschold income. By taking explicit account of these variations by estimating a willingnessto-pay function, we find that the improper use of marginal valuation estimates to calculate the benefits of nonmarginal improvements causes benefits to be overstated by approximately $30 \%$.

In the process of using our model to estimate households' willingness to pay, we found that the valuation placed on a marginal improvement in air quality is quite sensitive to the specification of the hedonic housing value equation. With plausible specifications of the relationship among air pollution, housing attributes, and housing values, aggregate benefit estimates may be reduced as much as $60 \%$ below the figure based on a constant marginal valuation. In contrast, the benefit estimates were found to be insensitive to the specification of the willingness-topay function. Neither modifying the functional form nor changing the specific variables included in the equation had a significant effect on the dollar value of benefits in the example we considered.

\section{APPENDIX: RESULTS FOR THE HOUSING VALUE EQUATION}

Most of the empirical results for the housing value equation are based on a common specification, as given in Eq. (A.1).

$$
\begin{gathered}
\log (M V)=a_{1}+a_{2} R M^{2}+a_{3} A G E+a_{4} \log (D I S)+a_{5} \log (R A D)+a_{6} T A X \\
+a_{7} P T R A T I O+a_{8}(B-0.63)^{2}+a_{9} \log (L S T A T)+a_{10} C R I M \\
+a_{11} Z N+a_{12} I N D U S+a_{13} C H A S+a_{14} N O X^{p}+\epsilon
\end{gathered}
$$

The study uses data for census tracts in the Boston Standard Metropolitan Statistical Area (SMSA) in 1970. With tracts containing no housing units or comprised entirely of institutions excluded, the Boston sample contains 506 census tracts. The definition of each variable, its expected sign, the data source, and the functional form in which each enters are indicated in Table IV. The sample means and standard deviations are reported in Table $\mathrm{V}$, and the simple correlations among variables are given in Table VI.

The data on 1970 air pollution concentrations used in this study were obtained from a meteorological model of the Boston air shed, the Transportation and Air Shed Simulation (TASSIM) Model developed by Gregory Ingram and others. ${ }^{33}$ The TASSIM model generates surfaces of mean air pollutant concentrations for the Boston SMSA which are then adjusted (or calibrated) using regression equations which compare TASSIM output to monitoring data ${ }^{34}$ Nine-

33 The TASSIM Model is described in [11].

${ }^{34}$ It is likely that individuals are sensitive to variations in pollution levels as well as annual means. For any averaging period, Larsen [18] found that the readings over 1 year were distributed log-normally, a distribution with two parameters (mean and variance). Thus, air pollution exposure at any given housing site would be completely described if the mean and variance for the year's readings were included. Not including the variance in our housing value equation might bias our results, although the strong correlations between moments of the frequence distribution suggests that the bias is not very great. Both Anderson and Crocker [1] and Wieand [35] reported that their results were not changed when other moments were added to the housing value equation. 


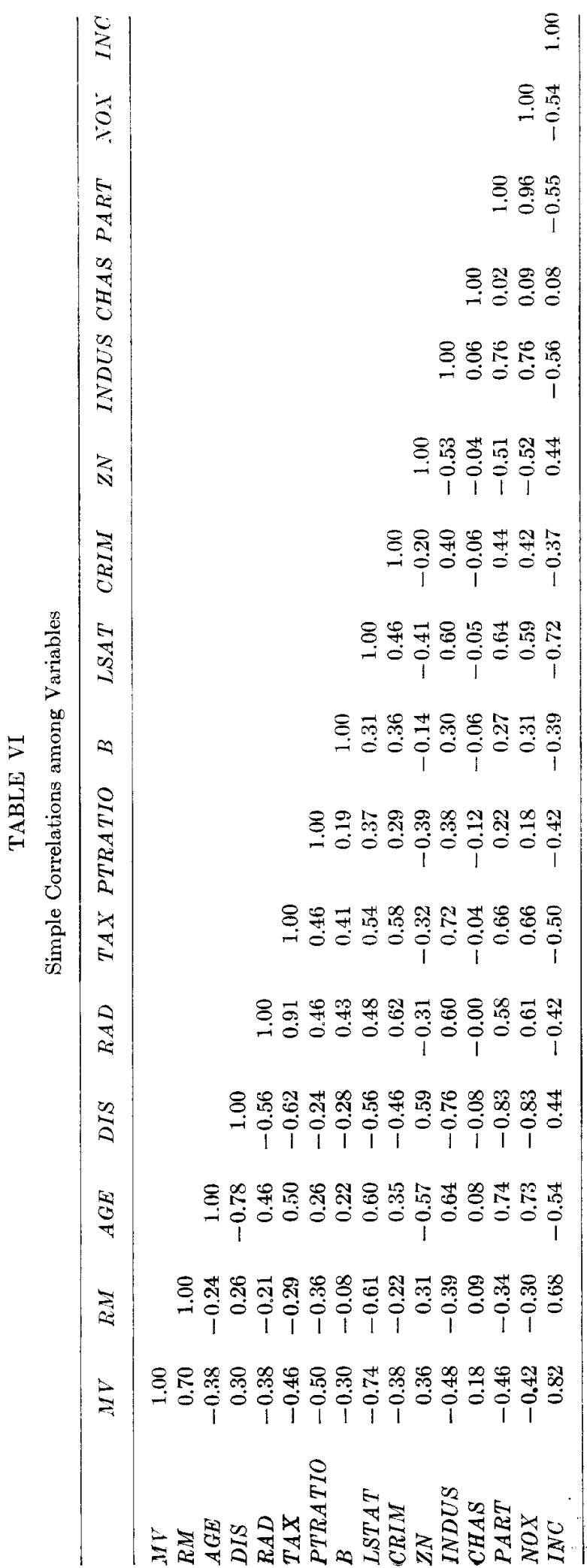


TABLE VII

Housing Value Equations ${ }^{a}$

\begin{tabular}{|c|c|c|c|}
\hline Variable & $\begin{array}{c}\text { "Basic equation" } \\
\text { Equation } 1\end{array}$ & $\begin{array}{c}\text { Basic equation } \\
\text { weighted } \\
\text { least squares } \\
\text { Equation } 2\end{array}$ & Equation 3 \\
\hline Dependent & $\log (M V)$ & $\log (M V)$ & $\log (M V)$ \\
\hline Constant & $\begin{array}{r}9.76 \\
(65.22)\end{array}$ & $\begin{array}{r}9.66 \\
(66.91)\end{array}$ & $\begin{array}{r}9.75 \\
(71.46)\end{array}$ \\
\hline$R M^{2}$ & $\begin{array}{r}0.0063 \\
(4.83)\end{array}$ & $\begin{array}{r}0.0057 \\
(4.53)\end{array}$ & $\begin{array}{r}0.0061 \\
(1.75)\end{array}$ \\
\hline$A G E$ & $\begin{array}{c}8.98 \times 10^{-5} \\
(1.7)\end{array}$ & $\begin{array}{c}1.26 \times 10^{-4} \\
(0.25)\end{array}$ & $\begin{array}{c}-8.78 \times 10^{-5} \\
(-0.17)\end{array}$ \\
\hline $\log (D I S)$ & $\begin{array}{r}-0.19 \\
(-5.73)\end{array}$ & $\begin{array}{r}-0.20 \\
(-6.21)\end{array}$ & $\begin{array}{r}-0.21 \\
(-6.53)\end{array}$ \\
\hline $\log (R A D)$ & $\begin{array}{r}0.096 \\
(5.00)\end{array}$ & $\begin{array}{r}0.107 \\
(5.94)\end{array}$ & $\begin{array}{r}0.082 \\
(4.43)\end{array}$ \\
\hline$T A X^{r}$ & $\begin{array}{c}-4.20 \times 10^{-4} \\
(-3.43)\end{array}$ & $\begin{array}{c}-3.53 \times 10^{-4} \\
(-3.09)\end{array}$ & $\begin{array}{c}-3.98 \times 10^{-4} \\
(-3.35)\end{array}$ \\
\hline PTRATIO & $\begin{array}{l}-0.031 \\
(-6.21)\end{array}$ & $\begin{array}{l}-0.030 \\
(-6.25)\end{array}$ & $\begin{array}{l}-0.033 \\
(-6.85)\end{array}$ \\
\hline$(B-0.63)^{2}$ & $\begin{array}{r}0.36 \\
(3.53)\end{array}$ & $\begin{array}{r}0.43 \\
(4.01)\end{array}$ & $\begin{array}{r}0.44 \\
(4.46)\end{array}$ \\
\hline $\log (S T A T)$ & $\begin{array}{r}-0.37 \\
(-14.84)\end{array}$ & $\begin{array}{r}-0.38 \\
(-16.24)\end{array}$ & $\begin{array}{r}-0.35 \\
(-14.39)\end{array}$ \\
\hline CRIM & $\begin{array}{l}-0.012 \\
(-9.53)\end{array}$ & $\begin{array}{l}-0.014 \\
(-8.00)\end{array}$ & $\begin{array}{l}-0.011 \\
(-9.26)\end{array}$ \\
\hline$Z N$ & $\begin{array}{c}8.03 \times 10^{-5} \\
(0.16)\end{array}$ & $\begin{array}{c}2.82 \times 10^{-4} \\
(0.58)\end{array}$ & $\begin{array}{c}4.25 \times 10^{-4} \\
(0.86)\end{array}$ \\
\hline$I N D U S$ & $\begin{array}{c}2.41 \times 10^{-4} \\
(0.10)\end{array}$ & $\begin{array}{c}-2.22 \times 10^{-4} \\
(-0.10)\end{array}$ & $\begin{array}{c}9.05 \times 10^{-4} \\
(0.40)\end{array}$ \\
\hline$C H A S$ & $\begin{array}{r}0.088 \\
(2.75)\end{array}$ & $\begin{array}{r}0.090 \\
(2.92)\end{array}$ & $\begin{array}{r}0.067 \\
(2.07)\end{array}$ \\
\hline$N O X^{p}$ & $\begin{array}{l}-0.0064 \\
(-5.64)\end{array}$ & $\begin{array}{l}-0.0058 \\
(-5.27)\end{array}$ & \\
\hline$P$ & 2 & 2 & \\
\hline$P A R T^{P P}$ & & & $\begin{array}{l}-0.051 \\
(-7.99)\end{array}$ \\
\hline$P P$ & & & 4 \\
\hline$R^{2}$ & 0.81 & & 0.82 \\
\hline
\end{tabular}

${ }^{a} t$ statisties are in parentheses.

teen stations monitor NOX and 18 monitor particulates. The fits of the calibration equations are quite good, the explained variance being $51 \%$ for the NOX equation and $84 \%$ for the PART equation. ${ }^{35}$

${ }^{35}$ Other housing value studies have not used a meteorological model to derive air pollutant concentrations but instead have obtained air pollution data for census tracts by extrapolating data from a relatively small number of monitoring stations. Kidker and Henning [27], Anderson and Crocker [1], and Wieand [35] all used St. Louis air pollution data derived from isopleth maps which were based on a maximum of 41 monitoring stations; Anderson and Crocker also used similar data from Washington, D. C., and Kansas City, although the number of monitoring stations was not given. Nelson [22] used Washington, D. C. data derived from between 9 and 26 mopitoring stations. 
Table VII gives the results of estimating Eq. (A.1) with $N O X^{p}$ in the equation, where $p$ is a parameter to be estimated. This is the "basic equation" used in the paper as the starting point for judging the sensitivity of the results to alternative specifications of the housing value equation. Table VII also contains the results of estimating the same housing value equation using weighted least squares and substituting PART for NOX.

\section{REFERENCES}

1. R. J. Anderson and T. D. Crocker, Air pollution and residential property values, Urb. Stud. 8, 171-180 (1971).

2. D. A. Belsley and V. C. Klema, Detecting and assessing the problems caused by multicollinearity: A use of the singular-value decomposition, Working Paper No. 66, National Bureau of Economic Research, Cambridge, Mass. (December 1974).

3. G. E. P. Box and D. R. Cox, An analysis of transformation, J. Roy. Sta.S. 26, 211-243 (1964).

4. D. B. Diamond, Income and residential location in urban areas, University of Chicago, Chicago, Ill. (December 1975).

5. A. M. Freeman, On estimating air pollution control benefits from land value studies, J. Envir. Manag. 1, 74-83 (May 1974).

6. H. Glesjer, A new test of heteroscedasticity, J. Am. Stat. A. 64, 316-323, (1969).

7. S. M. Goldfeld and R. E. Quandt, "Nonlinear Methods in Econometrics," North-Holland, Amsterdam, Holland (1972).

8. Z. Griliches, Introduction: Hedonic prices revisited, in "Price Indexes and Quality Change" (Griliches, Ed.), Harvard University Press, Cambridge, Mass. (1971).

9. D. Harrison, Jr., "Who Pays for Clean Air: The Cost and Benefit Distribution of Federal Automobile Emission Standards," Ballinger, Cambridge, Mass. (1975).

10. D. Harrison, Jr., and R. N. McDonald, Willingness to pay in Boston and Los Angeles for a reduction in automobile-reJated pollutants, in "A Report by the Coordinating Committee on Air Quality Studies" (National Academy of Sciences), prepared for the Committee on Public Works, U. S. Senate, "Volume IV: The Costs and Benefits of Automobile Emission Control," U. S. Government Printing Office, Washington, D. C. (September 1974).

11. G. K. Ingram and G. R. Fauth, "TASSIM: A Transportation and Air Shed Simulation Model," Final Report to the U. S. Department of Transportation, National Technical Information Service, Springfield, Va. (May 1974).

12. J. F. Kain and J. M. Quigley, Measuring the value of housing quality, J. Amer. Stat. A., 65, 532-548 (May 1970).

13. J. F. Kain and J. M. Quigley, "Housing Markets and Racial Discrimination: A Microeconomic Analysis," National Bureau of Economic Research, New York, NY (1975).

14. A. King, The demand for housing: A Lancasterian approach, University of Maryland, College Park, Md. (January 1975).

15. A. King and P. Mieszkowski, Racial discrimination, segregation, and the price of housing, J. Polit. Econ. 81, 590-606 (May/June 1973).

16. J. Kmenta, "Elements of Econometrics," Macmillan, New York, NY (1971).

17. K. J. Lancaster, New approach to consumer theory, J. Polit. Econ. 74, 132-157 (April $1966)$.

18. R. I. Larsen, A mathematical model for relating air quality measurements to air quality standards, U. S. Environmental Protection Agency, Washington, D. C., Report AP-89 (November 1971).

19. L. B. Lave and E. P. Seskin, Air pollution and human health, Science, 169, 723-733 (August 21, 1970).

20. R. E. B. Lucas, Hedonic price functions, Econ. Inq. XIII, 2, 157-178 (June 1975).

21. J. Muellbauer, Household production theory, quality, and the hedonic technique, Amer. Econ. Rev. 64, 977-993 (December 1974).

22. J. P. Nelson, Residential choices, hedonic prices, and urban air quality, J. Urb. Econ. (forthcoming). 
23. R. E. Park, Estimation with heteroscedastic error terms, Econometric 34, 888 (1966).

24. A. M. Polinsky and D. L. Rubinfeld, Property values and the benefits of environmental improvements: 'Theory and measurement, in "Public Economics and the Quality of Life" (Wingo and Evans, Eds.), Johns Hopkins, Baltimore (1977).

25. A. M. Polinsky and D. L. Rubinfeld, The long run effects of a residential property tax and local public services, J. Urb. Econ., in press.

26. R. A. Pollack and M. L. Wachter, The relevance of the household production function and its implications for the allocation of time, J. Polit. Econ. 83, 255-277 (April 1975).

27. R. G. Ridker and J. A. Henning, The determinants of residential property values with special reference to air pollution, Rev. Econ. St. 49, 246-257 (May 1967).

28. S. Rosen, Hedonic prices and implicit markets, J. Polit. Econ. 82, I, 34-55 (January 1974).

29. A. Schnare, An empirical analysis of the dimensions of neighborhood quality, Unpublished Ph.D. Dissertation, Harvard University (1973).

30. K. A. Small, Air pollution and property values: Further comment, Rev. Econ. St. 47, 1, 105-107 (February 1975).

31. V. K. Smith, Residential location and environmental amenities, State University of New York, Binghamton, NY (March 1976).

32. M. R. Straszheim, Hedonic estimation of housing market prices: A further comment, Rev. Econ. St. 51, 404-406 (August 1974).

33. Vogt, Ivers, and Associates, Comprehensive land use inventory report, Department of Commerce and Development, Commonwealth of Massachusetts, Boston, Mass. (1965).

34. R. E. Welsch, Regression sensitivity analysis and bounded influence estimation in "Evaluation of Econometric Models" (Kmenta and Ramsey, Eds.) Academic Press, New York (forthcoming).

35. K. F. Wieand, Air pollution and property values: A study of the St. Louis area, J. Reg. Sci. 13, 91-95 (April 1973). 